\title{
Lyme disease in Canada: Q \& A for paediatricians
}

\section{WHAT IS LYME DISEASE?}

Lyme disease is a tick-borne infection caused by the spirochete Borrelia burgdorferi. The infection is transmitted to humans through the bite of the Ixodes scapularis tick in eastern Canada and Ixodes pacificus in western Canada (1).

\section{HOW COMMON IS LYME DISEASE IN CANADA?}

Lyme disease is the most common tick-borne infection in North America and Europe, but it is not common in Canada. The western black-legged ticks (I pacificus) are distributed widely in British Columbia and are well established in the lower mainland, Fraser Valley and on Vancouver Island. The eastern black-legged ticks (I scapularis) have a more patchy distribution and are well established in some locations in Ontario along the shores of Lake Erie and Lake Ontario, in southeastern Manitoba, and in Bedford and the Lunenburg area of Nova Scotia $(1,2)$. Ixodes ticks are found intermittently in most provinces in Canada, likely brought by migratory birds; $10 \%$ to $12 \%$ of these ticks may carry B borgdorferi (3). Therefore, one could theoretically acquire Lyme disease from the bite of an infected tick anywhere in Canada but the chances are quite low, except in areas where the eastern and western black-legged tick populations are firmly established. Human cases of Lyme disease in Canada are primarily the result of travel to areas outside of Canada or areas in Canada mentioned above where infected ticks are well established. Lyme disease cannot be transmitted by the American dog tick (Dermacentor variabilis) or the groundhog tick (Ixodes cookei), which are among the most common ticks found on people and pets in Canada.

The incidence of Lyme disease in Canada is not known because it is not a nationally notifiable disease, but it is reportable in certain provinces where the vector ticks are well established. In Ontario, Lyme disease is a reportable disease and all cases are investigated by public health units. Between 1999 and 2004, a total of 172 cases of Lyme disease were reported in Ontario, of which 110 (64\%) were travel related; only 31 $(18 \%)$ were known to have been acquired locally (4). The number of endemic cases reported in Ontario (five to 10 per year) has not increased over the past two decades (4).

\section{WHAT ARE THE CLINICAL MANIFESTATIONS OF LYME DISEASE?}

Clinical manifestations of Lyme disease may involve the skin, nervous system, heart and joints; both early and late manifestations of the disease are observed. Erythema migrans is the most common early manifestation of Lyme disease. It typically develops between seven and 14 days after detachment of the tick, although a range between three and 30 days has been reported (5). This rash usually begins as an erythematous macule or papule that rapidly expands centrifugally, often with central clearing. The lesions (usually single, but can be multiple) may be round or oval and either flat or slightly raised, and typically reach at least $5 \mathrm{~cm}$ in diameter. Erythema migrans is often accompanied by systemic symptoms of arthralgia, headache and fatigue; fever may also be associated with early disease. Early Lyme disease can occur without erythema migrans, although a clinical diagnosis is difficult in the absence of erythema migrans because of the similarity of the systemic symptoms to those of a viral infection. Without treatment, erythema migrans resolves spontaneously in a mean of four weeks. Late Lyme disease is a result of the spirochetemia that occurs during the early stages of the infection with dissemination to one or more organs. More than $50 \%$ of patients with untreated erythema migrans will develop arthritis (most often involving the knees), approximately $10 \%$ will develop neurological disease (facial nerve palsy [most commonly] and meningitis) and approximately 5\% will develop cardiac manifestations (atrioventricular block).

In a small number of patients, usually mild subjective symptoms of fatigue, musculoskeletal pain, and difficulties with short-term memory and concentration persist for many months after appropriate treatment. These typically selflimiting symptoms have been collectively termed post-Lyme disease syndrome (6).

Chronic Lyme disease is a poorly defined entity used by some Lyme disease practitioners to describe patients with postLyme disease symptoms and a variety of unrelated symptom complexes that are ascribed to persistent infection with B burgdorferi (7). Evidence suggests that persistent infection with B burgdorferi occurs extremely rarely after adequate treatment. Some experts suggest that chronic Lyme disease is a term used to diagnose unexplained medical symptoms rather than a syndrome resulting from infection with B burgdorferi (6).

\section{HOW IS THE DIAGNOSIS OF LYME DISEASE MADE?}

If a patient presents with a skin rash typical of erythema migrans and has had exposure in a region where the black-legged tick is established, a diagnosis of Lyme disease should be made on clinical grounds alone. In areas of the country where black-legged ticks have been found but populations are not known to be established, a diagnosis based on clinical findings alone is more

Correspondence: Canadian Paediatric Society, 2305 St Laurent Boulevard, Ottawa, Ontario K1G 4J8. Telephone 613-526-9397,

fax 613-526-3332, Web sites www.cps.ca, www.caringforkids.cps.ca 
difficult. For rashes occurring in these areas or if the rash is not typical, laboratory confirmation is recommended. Laboratory diagnosis of Lyme disease is accomplished based on demonstration of a serological response to B burgdorferi.

\section{HOW RELIABLE ARE THE LABORATORY TESTS OF LYME DISEASE?}

Serological testing is recommended when patients have a rash suggestive of erythema migrans outside of the appropriate season in a tick-established area or in an area of the country where the tick is not established. Testing is also suggested for patients with characteristic neurological, cardiac or joint involvement with a reasonable possibility of exposure to black-legged ticks. Immunoglobulin $\mathrm{M}$ antibodies are usually detectable within weeks of the onset of symptoms; however, a substantial proportion of patients will not have antibodies present at the time of clinical presentation. Therefore, repeat testing four weeks after an initially negative test is suggested. Antibody measurement by enzyme immunoassay is sensitive but lacks specificity; therefore, a two-step procedure with confirmation of positive enzyme immunoassay results by Western blot is recommended with interpretation of the Western blot results using the Centers for Disease Control and Prevention (USA) guidelines (8). It is common for private laboratories in the United States to omit the confirmation step, resulting in a large percentage of positive results. Care should be taken to send specimens to laboratories that use the two-step process and adhere to the Canadian guidelines (2). Even with the two-step procedure, the likelihood of a false-positive test is high in a low prevalence area such as Canada; therefore, serological screening of Lyme disease is strongly discouraged.

\section{WHAT IS THE TREATMENT FOR LYME DISEASE?}

The treatment of Lyme disease should follow the clinical practice guidelines of the Infectious Diseases Society of America (9); only a brief summary will be provided in the present note. Antibiotic prophylaxis is generally not warranted and treatment should be given only after a diagnosis of Lyme disease has been made. Early Lyme disease (erythema migrans) in children is treated orally with amoxicillin $(50 \mathrm{mg} / \mathrm{kg} /$ day in three divided doses; maximum $500 \mathrm{mg} /$ dose) or cefuroxime axetil $(30 \mathrm{mg} / \mathrm{kg} /$ day in two divided doses; maximum $500 \mathrm{mg} /$ dose). If the child is eight years of age or older, doxycycline $(4 \mathrm{mg} / \mathrm{kg} /$ day in two divided doses; maximum $100 \mathrm{mg} / \mathrm{dose}$ ) is administered for 14 to 21 days. If the first-line drugs are contraindicated, certain macrolide antibiotics can be used as an alternative, but they may be less effective. Children with central nervous system manifestations of Lyme disease should be treated with parenteral ceftriaxone for 14 to 28 days, although there are some data to support the effectiveness of the oral antibiotic regimens in central nervous system disease without parenchymal involvement (eg, facial nerve palsy) (10). Heart block related to Lyme disease should initially be treated parenterally, with a total course of antibiotics for 14 to 21 days. Lyme arthritis without concomitant neurological involvement can usually be treated orally with a one-month course of amoxicillin or doxycycline, resulting in the resolution of arthritis in most (approximately 90\%) patients (11). For patients who have had improvement during or after a recommended course of oral antibiotics but who have persistent or recurrent joint swelling, a second four-week course of oral antibiotics is recommended. For those patients who have had little or no improvement with the first course of antibiotics, four weeks of intravenous ceftriaxone is recommended. If arthritis persists and polymerase chain reaction testing for B burgdorferi DNA in joint fluid is positive, retreatment with an additional one month of oral antibiotics may be considered even though polymerase chain reaction results may remain positive in joint fluid for several weeks after the spirochetes have been eliminated. Longer courses of antibiotics are unlikely to be effective and increase the risk of adverse events (11).

There are physicians who believe that Lyme disease is commonly underdiagnosed, and that a significant number of patients with a wide variety of symptoms would benefit from prolonged courses of parenteral antibiotics. There are no scientifically valid data to support this and, therefore, it is not recommended $(9,10,12)$.

\section{HOW SHOULD PERSISTENT JOINT SYMPTOMS BE MANAGED?}

For patients with ongoing arthritis, despite treatment with oral and intravenous antibiotics as described above, treatment with a nonsteroidal anti-inflammatory drug (NSAID) and consultation with an expert are recommended. If arthritis persists despite treatment with NSAIDs, hydroxychloroquine is recommended because it may provide both an anti-inflammatory and an antispirochetal effect. Intraarticular corticosteroids are not recommended before antibiotic treatment and may be a risk for persistent arthritis (11). If arthritis remains active for over one year, arthroscopic synovectomy may be considered. More aggressive second-line therapy including the use of methotrexate and infliximab has been reported in patients with Lyme arthritis; however, efficacy is not proven and these treatments are not recommended if there is active infection (11). It is important to remember that Lyme arthritis eventually resolves in all patients, although joint damage may occur in some patients. Antibiotic treatment appears to decrease the total duration of arthritis, even in patients with persistent arthritis after currently recommended antibiotic regimens, and second-line therapy with NSAIDS and hydroxychloroquine appears to decrease the severity of joint inflammation.

\section{WHAT ARE RELIABLE SOURCES OF INFORMATION?}

- Public Health Agency of Canada

o General information <www.phac-aspc.gc.ca/id-mi/ lyme-eng.php> (Version current at January 20, 2009). 
o Fact sheet <www.phac-aspc.gc.ca/id-mi/lyme-fs-eng. php $>$ (Version current at January 20, 2009).

- Infectious Diseases Society of America (treatment guidelines) <http://www.journals.uchicago.edu/doi/pdf/1

\section{REFERENCES}

1. Ogden NH, Trudel L, Artsob H, et al. Ixodes scapularis ticks collected by passive surveillance in Canada: Analysis of geographic distribution and infection with the Lyme borreliosis agent Borrelia burgdorferi. J Med Entomol 2006;43:600-9.

2. Canadian Public Health Laboratory Network. The laboratory diagnosis of Lyme borreliosis: Guidelines from the Canadian Public Health Laboratory Network. Can J Infect Dis Med Microbiol 2007;18:145-8.

3. Ogden NH, Barker IK, Beauchamp G, et al. Investigation of ground level and remote-sensed data for habitat classification and prediction of survival of Ixodes scapularis in habitats of southeastern Canada. J Med Entomol 2006;43:403-14.

4. Vrbova L, Middleton D. Descriptive epidemiology of Lyme disease in Ontario: 1999-2004. Can Commun Dis Rep 2006;32:247-57.

5. Wormser GP. Clinical practice. Early Lyme disease. N Engl J Med 2006;354:2794-801.

6. Feder HM Jr, Johnson BJ, O'Connell S, et al. A critical appraisal of "chronic Lyme disease". N Engl J Med 2007;357:1422-30. (Erratum in 2008;358:1084).

7. Cameron D, Gaito A, Harris N, et al; ILADS Working Group. Evidence-based guidelines for the management of Lyme disease. Expert Rev Anti Infect Ther 2004;2:S1-13.
0.1086/508667? cookiesSet=1\&cookieSet $=1>$

(Version current at January 20, 2009).

- Centers for Disease Control and Prevention <www.cdc.gov/ ncidod/dvbid/lyme/> (Version current at January 20, 2009).
8. Centers for Disease Control and Prevention (CDC). Notice to Readers Recommendations for Test Performance and Interpretation from the Second National Conference on Serologic Diagnosis of Lyme Disease. MMWR 1995;44:590-1.

9. Wormser GP, Dattwyler RJ, Shapiro ED, et al. The clinical assessment, treatment, and prevention of Lyme disease, human granulocytic anaplasmosis, and bebesiosis: Clinical practice guidelines by the Infectious Diseases Society of America. Clin Infect Dis 2006;43:1089-134. (Erratum in 2007;45:941). $<$ http://www.journals.uchicago.edu/doi/pdf/10.1086/508667? cookies Set $=1 \&$ cookieSet $=1>$ (Version current at January 20, 2009).

10. Halperin JJ, Shapiro ED, Logigian E, et al; Quality Standards Subcommittee of the American Academy of Neurology. Practice parameter: Treatment of nervous system Lyme disease (an evidencebased review): Report of the Quality Standards Subcommittee of the American Academy of Neurology. Neurology 2007;69:91-102.

11. Steere AC, Angelis SM. Therapy for Lyme arthritis: Strategies for the treatment of antibiotic-refractory arthritis. Arthritis Rheum 2006;54:3079-86.

12. Bowie WR. Guidelines for the management of Lyme disease: The controversy and the quandary. Drugs 2007;67:2661-6.

\section{INFECTIOUS DISEASES AND IMMUNIZATION COMMITTEE}

Members: Drs Robert Bortolussi, IWK Health Centre, Halifax, Nova Scotia (chair); Dorothy L Moore, The Montreal Children's Hospital, Montreal, Quebec; Joan L Robinson, Edmonton, Alberta; Élisabeth Rousseau-Harsany, Sainte-Justine UHC, Montreal, Quebec (board representative); Lindy M Samson, Children's Hospital of Eastern Ontario, Ottawa, Ontario

Consultant: Dr Noni E MacDonald, IWK Health Centre, Halifax, Nova Scotia

Liaisons: Drs Upton D Allen, The Hospital for Sick Children, Toronto, Ontario (Canadian Pediatric AIDS Research Group); Scott A Halperin, IWK Health Centre, Halifax, Nova Scotia (Immunization Program, ACTive); Charles PS Hui, Children's Hospital of Eastern Ontario, Ottawa, Ontario (Health Canada, Committee to Advise on Tropical Medicine and Travel); Larry Pickering, Elk Grove Village, Illinois, USA (American Academy of Pediatrics, Red Book Editor and ex-officio member of the Committee on Infectious Diseases); Marina I Salvadori, Children's Hospital of Western Ontario, London, Ontario (Health Canada, National Advisory Committee on Immunization)

Principal authors: Drs Scott A Halperin, IWK Health Centre, Halifax, Nova Scotia; Bianca Lang, IWK Health Centre, Halifax, Nova Scotia

The recommendations in this statement do not indicate an exclusive course of treatment or procedure to be followed. Variations, taking into account individual circumstances, may be appropriate.

All Canadian Paediatric Society position statements/notes are reviewed, revised or retired as needed on a regular basis.

For the current version, please consult the "Position Statements" section of the CPS website (www.cps.ca/english/publications/statementsindex.htm). This article also appeared in the February 2009 issue of Paediatrics $\mathcal{E}$ Child Health. 


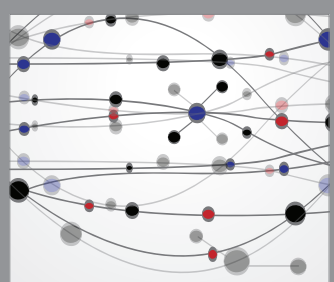

The Scientific World Journal
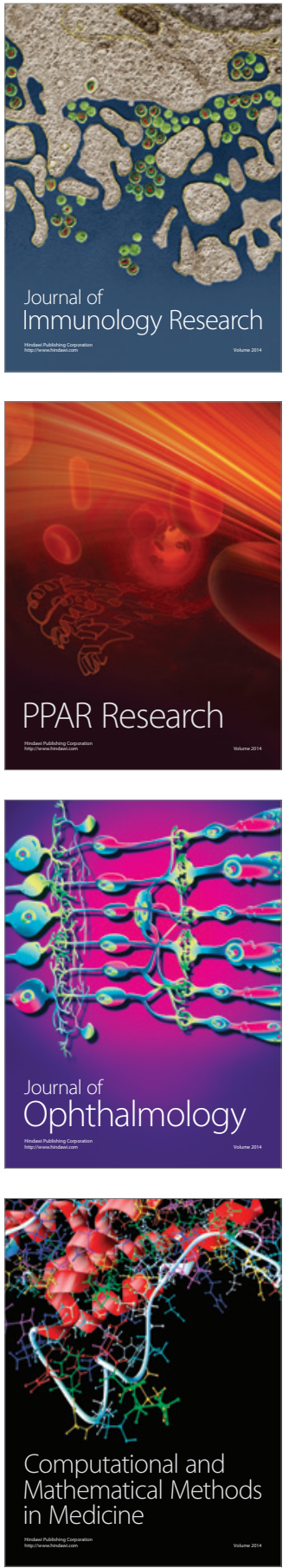

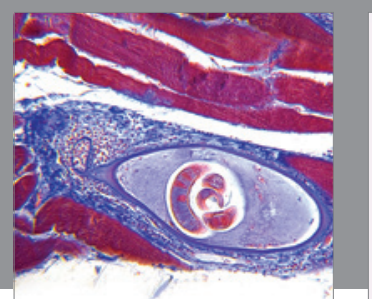

Gastroenterology Research and Practice

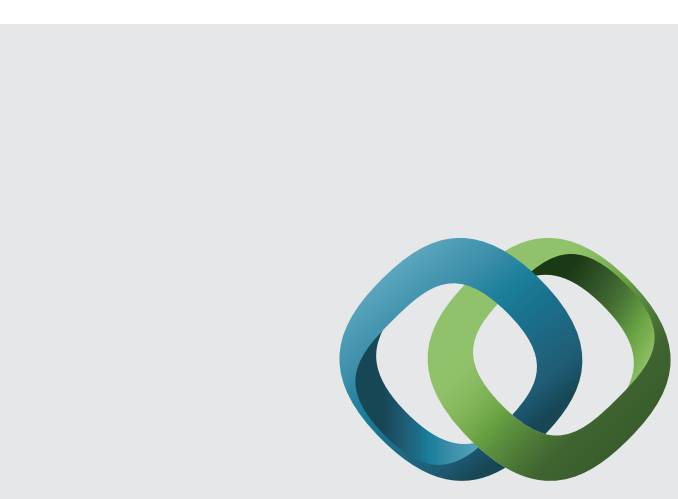

\section{Hindawi}

Submit your manuscripts at

http://www.hindawi.com
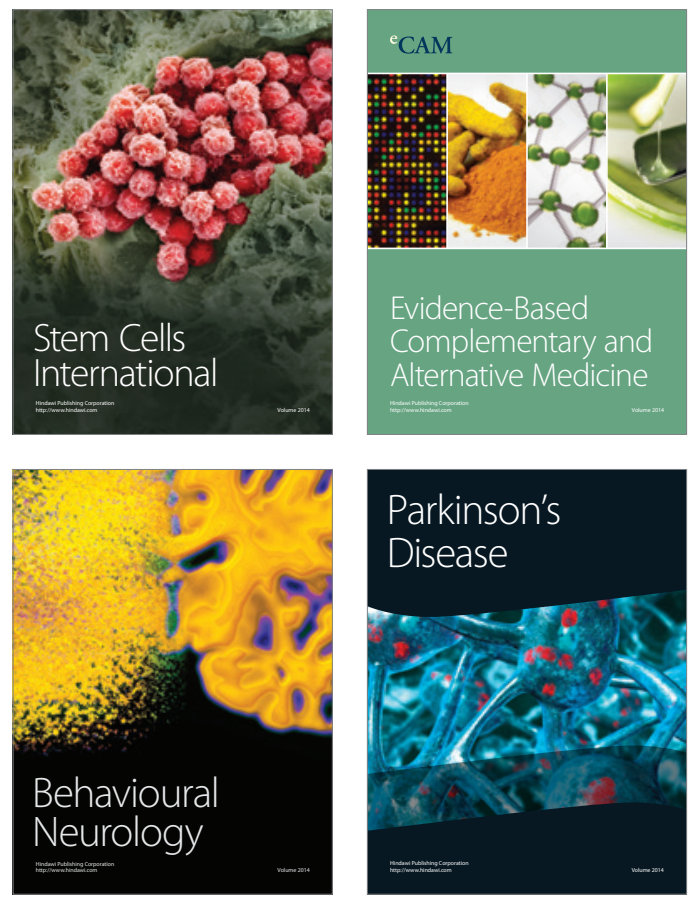
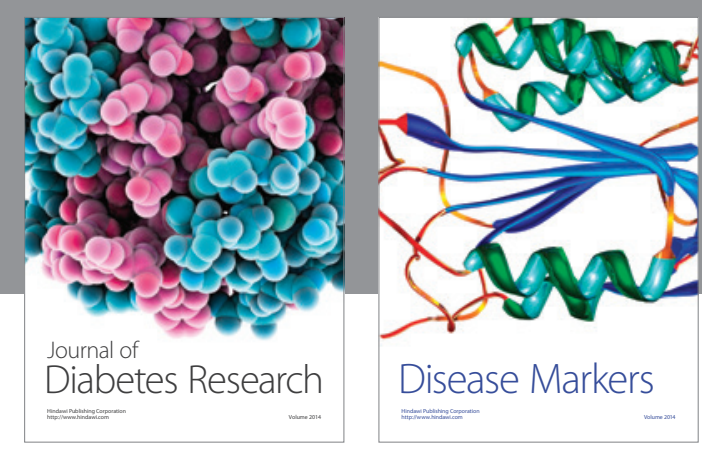

Disease Markers
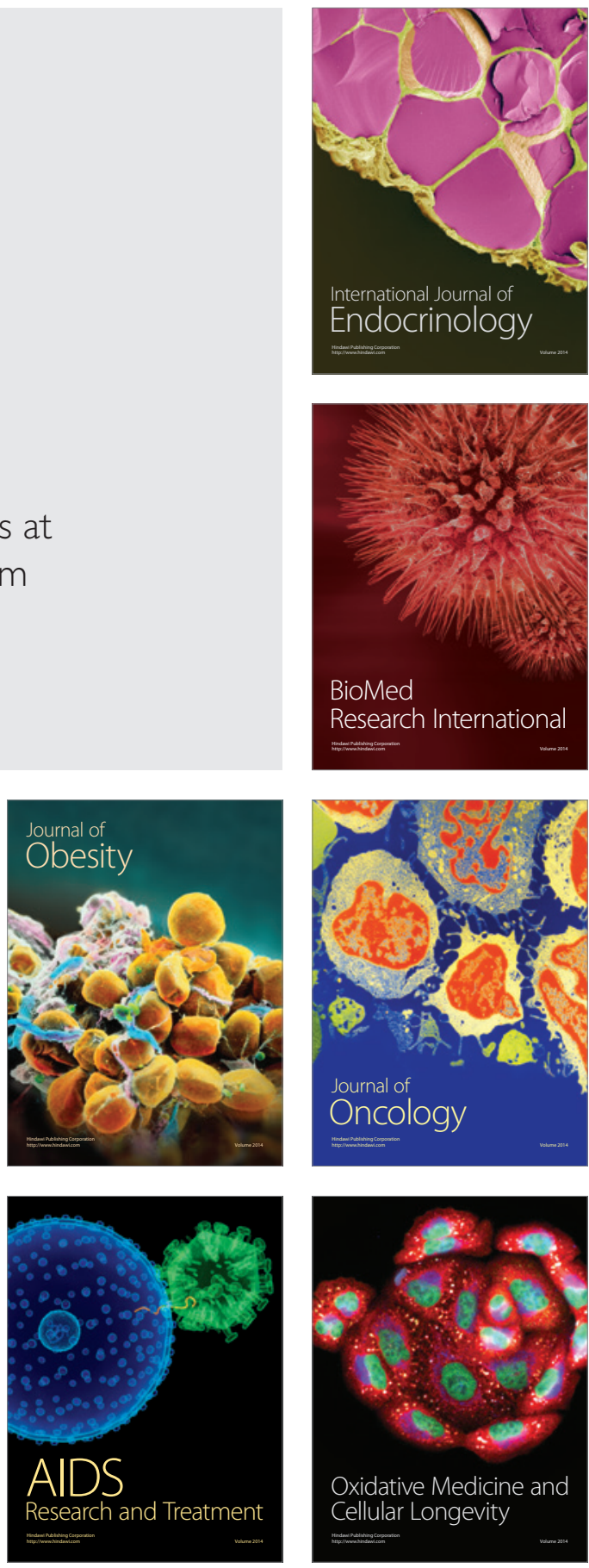